\title{
Congruencia programática entre partidos y votantes en Chile
}

\author{
Mauricio Morales Quiroga*
}

\section{Resumen}

El sistema de partidos chileno suele ser clasificado como uno de los más programáticos de América Latina. Se asume que existe una alta congruencia entre partidos y votantes. Sin embargo, el partido más incongruente con la ciudadanía es el que hoy tiene la bancada de diputados más grande. En consecuencia, Chile es un caso útil para discutir dos afirmaciones centrales de la literatura. Primero, que los sistemas de partidos institucionalizados se caracterizan por una fuerte estructuración programática de las preferencias y segundo, que la proximidad programática entre partidos y electores es condición necesaria para el éxito electoral. El análisis de datos está hecho sobre la base de dos estudios de opinión aplicados al total de diputados y senadores en ejercicio en 2010 y 2011-2012 y de dos encuestas nacionales de ciudadanos en idénticos años.

\begin{abstract}
The Chilean party system tends to be classified as one of the most programmatic in Latin America. It is assumed that there is a high consistency between parties and voters. However, the most incongruous party with the citizenship is the one that today has the largest base of members. As a result, Chile is a useful case to discuss two central claims of literature. First, institutionalized party systems are characterized by a strong programmatic structure of preferences and secondly, the programmatic closeness between parties and voters is a necessary condition for electoral success. Data analysis is based on two opinion studies applied to the total number of deputies and senators who exercised during 2010 and 2011-2012, and two national citizen surveys conducted in the same years.
\end{abstract}

Palabras clave: congruencia, partidos, sistemas de partidos, elecciones, Chile, votantes, representantes.

Keywords: congruence, parties, party systems, elections, Chile, voters, representatives.

* Doctor en ciencia política, Pomtificia Universidad Católica, Chile. Académico de tiempo completo en la Escuela de Ciencia Política de la Universidad Diego Portales, Chile. Este artículo se inscribe en el proyecto Fondecyt número 1130022 titulado "Los arraigados de siempre. La identificación con partidos en Chile pre-1973 y post-1990". La encuesta a congresistas se realizó en el marco de un proyecto sobre brechas de representación realizado por la Universidad Diego Portales y financiado por la Fundación Ford. 


\title{
Introducción
}

\author{
El problema
}

hile suele ser clasificado como uno de los países con mayores niveles de institucionalización de su sistema de partidos (Mainwaring y Scully, 1995; Payne et al., 2003). Es decir, con estabilidad de la competencia partidaria y bajos niveles de volatilidad electoral. Frecuentemente, dicha institucionalización se asocia con una alta estructuración programática de las preferencias políticas. Esto implica que los partidos son distinguibles en el eje izquierda-derecha y que los votantes suelen ser congruentes con las agendas programáticas de los partidos. La combinación entre institucionalización y congruencia programática, entonces, facilita la estabilidad del régimen político y la gobernabilidad democrática.

No obstante, recientes estudios han comenzado a cuestionar dichos supuestos (Morales, 2010; Luna y Altman, 2011), clasificando el caso chileno como un sistema de partidos hidropónico (Zucco, 2009). Es decir, estable en términos de desempeño electoral de los partidos, aunque con algunos de débil raigambre social, lo que se refleja en las altas tasas de no identificación. La encuesta de la Universidad Diego Portales (UDP) de septiembre de 2013 arrojó un 80 por ciento de desafección con los partidos, el porcentaje más alto desde que comenzó esta encuesta (2005), a lo que se suma una sistemática caída en la confianza hacia las instituciones. Ahora bien, dicho carácter hidropónico del sistema de partidos (que supone estabilidad) convive con altos niveles de estructuración programática de las preferencias en comparación con el resto de los países latinoamericanos exceptuando Uruguay (Luna y Zechmeister, 2005; Kitschelt et al., 2010). Los partidos y sus votantes se ordenarían sistemáticamente en un eje izquierda-derecha. En consecuencia, éstos tendrían agendas diferentes y programas claramente distinguibles, sucediendo lo mismo con los electores. Esto tiene como soporte la comparación de opiniones entre votantes y representantes.

En este artículo se sostiene algo diferente. Por una parte, se adhiere a la idea de que Chile es un sistema de partidos hidropónico que combina baja volatilidad y baja identificación, lo que es contradictorio para los enfoques de la institucionalización partidaria (Mainwaring, 1999; Morales, 2012a). Por otra, se estima que en Chile se ha producido un estancamiento de la estructuración programática de las preferencias electorales. Naturalmente, la vinculación programática fue robusta al inicio de la "Nueva Democracia" 
(1989), dada la fuerte polarización entre partidarios y opositores al régimen de Pinochet. Tal división política ha definido la intención de voto de los chilenos (Huneeus, 2003), aunque con menor capacidad predictiva con el paso del tiempo. La menor densidad programática de las preferencias puede observarse al constatar que el partido más votado -la Unión Demócrata Independiente (UDI)- es el más incongruente con la ciudadanía, pero también es el que más gasta en campañas. Si bien esta evidencia no es suficiente para afirmar que Chile transita de un sistema de partidos programático a otro de carácter no programático, sí indica que es posible que partidos ideológicamente distantes del votante mediano sean electoralmente exitosos.

¿Qué podría explicar esta aparente contradicción? Teóricamente, y secundando a Serra (2010), el éxito de candidatos pertenecientes a partidos incongruentes se debe a una estrategia de largo plazo asociada con la inversión de recursos. Estos candidatos gastan dinero con el afán de fortalecer sus atributos personales y así dejar en segundo plano sus orientaciones políticas que, como ellos mismos saben, no sintonizan con su propio electorado. Como resultado, no es tan extraña la combinación entre candidatos con un alto apoyo electoral, pero sin una vinculación programática con los votantes (Ashworth y Bueno de Mesquita, 2007; Meirowitz, 2008). En el caso de Chile, el éxito electoral de la Unión Democrática Independiente (UDI) en los segmentos más pobres, por ejemplo, se explica sustantivamente por la cantidad de dinero que invierte para posicionar a sus candidatos (Luna, 2010).

Visto de esta manera, resulta un tanto discutible la relación de vinculación programática entre partidos y electores, institucionalización y calidad de la democracia. Luna y Zechmeister (2010) avanzan en esta discusión, particularmente al sostener que no existe una relación lineal entre vinculación programática e institucionalización. Al parecer, existen otros caminos o rutas para llegar a sistemas de partidos institucionalizados. Honduras es un buen ejemplo de ello, pues justamente es clasificado por Mainwaring y Scully (1995) y por Payne et al. (2003) como uno de los sistemas más institucionalizados de la región, pero también es uno de los menos programáticos (Morales, 2014). Mainwaring y Torcal (2005), en tanto, defienden la idea de que mayores niveles de institucionalización conducen o están relacionados con una mayor calidad de la democracia. Los autores están en lo correcto, pero de cualquier forma, hay casos que escapan a esta relación. Nuevamente Honduras es ejemplo de ello.

La figura 1 reproduce parte de la argumentación teórica general. La propuesta de este artículo es que, en realidad, el argumento lineal entre los componentes de la institucionalización, la congruencia programática 
entre partidos y electores y la calidad de la democracia no es necesariamente correcto. Como se dijo, existen países con alto raigambre social de los partidos (identificación). Algunos conviven con alta (Paraguay) y otros con baja volatilidad (Honduras). Al mismo tiempo, existen países con baja identificación y baja volatilidad (Chile, Brasil). Por tanto, las dos dimensiones más destacadas del índice de institucionalización (identificación y volatilidad), no necesariamente tienen una relación lineal directa. Un caso teóricamente consistente es el de Uruguay, con alta identificación con partidos, baja volatilidad, alta institucionalización y alta calidad de la democracia (Levine y Molina, 2007).

Figura 1. Institucionalización, congruencia y calidad de la democracia

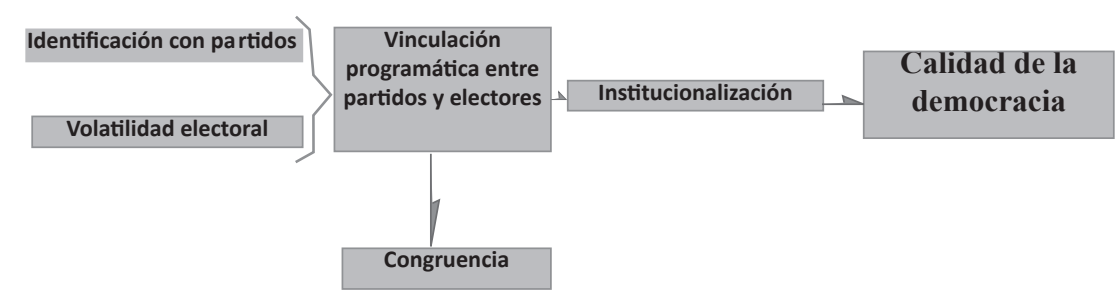

Fuente: Elaboración propia.

El punto clave para aclarar la discusión está, a mi juicio, en observar tanto la magnitud como el tipo de la identificación partidaria que predomina en cada país. En Honduras y Paraguay, por ejemplo, la identificación es alta respecto al promedio latinoamericano (ver tabla 2), aunque en contextos de sistemas de partidos claramente clientelares (Abente, 2006; Artiga, 2000; Torres-Rivas, 2007). Es decir, una alta magnitud de identificación con partidos no necesariamente equivale a una alta vinculación programática entre electores y partidos o a una alta institucionalización de un sistema de éstos. Por cierto, una alta identificación con partidos tampoco conduce necesariamente a una alta calidad de la democracia. Uruguay y Chile puntúan alto en el índice de calidad de la democracia (Levine y Molina, 2007; ver tabla 2), pero mientras Uruguay presenta una de las tasas de identificación con partidos más alta de la región, Chile ocupa los últimos lugares.

\section{El argumento}

Lo anterior sirve como acertijo teórico para abordar el caso de Chile. Hay quienes ven en Chile un ejemplo de congruencia programática entre parti- 
dos y electores (Luna y Zechmeister, 2010). Otros, en cambio, reconocen esta congruencia y sostienen que la baja identificación con partidos y confianza en las instituciones obedecen a la "partidocracia" que predomina en el país (Siavelis, 2009). Lo que se sostiene en este artículo es que ambas visiones, si bien contribuyen a entender mejor el caso de Chile en perspectiva comparada, adolecen de un análisis más profundo sobre la congruencia entre partidos y electores. En este trabajo muestro que esa supuesta congruencia entre partidos y electores es absolutamente cuestionable al desagregar los resultados por cada una de las coaliciones. Si se observan los totales de representantes y votantes, es factible sostener la tesis de que existe congruencia entre partidos y electores. Sin embargo, si estos totales se segmentan según las coaliciones más importantes, los resultados no dejan de sorprender. Existe mayor congruencia entre lo que opinan los congresistas de la Concertación, sus votantes y el resto de la población. No sucede lo mismo cuando se trata de comparar a los congresistas de la Alianza, pues emergen grandes diferencias. No obstante, son precisamente los partidos de la Alianza los que más han crecido electoralmente. Esto retrata un sistema de partidos que, por lo bajo, ha visto caer no sólo la magnitud de la identificación, también la vinculación programática entre partidos y electores.

No es usual que en un sistema aparentemente institucionalizado, el partido menos congruente con los ciudadanos aumente sus niveles de votación y que el partido más congruente los disminuya. Esto se explica por la reducción de los niveles de polarización programática que caracterizaron a la política chilena de la post-transición. En otras palabras, el debilitamiento de los clivajes societales como predictores de la intención de voto va asociado con un incremento de los niveles de personalización de la política. Efectivamente, el sistema electoral binominal que rige las elecciones de diputados es uno de los más personalizados en América Latina (Hallerberg y Marier, 2004: 577). Entonces, en este escenario aumenta la relevancia de los candidatos y la influencia del dinero en las campañas. Por ende, la proximidad programática entre partidos y electores deja de ser condición necesaria para el éxito electoral, dando paso a una proximidad pragmática o a una relación de mayor intensidad entre partidos y votantes (Iversen, 1994).

En un ambiente de polarización, la proximidad programática es un factor clave para sumar apoyos. Los partidos son claramente distinguibles en los ejes clásicos de izquierda-derecha, estado-mercado y liberal-conservador. Los electores votan por esos partidos en función de sus plataformas programáticas. No obstante, cuando la polarización se reduce o se debilita dada la distancia con la elección inaugural de la democracia (1989 en el caso de 
Chile) y, al mismo tiempo que se reduce la fuerza de la división entre autoritarismo y democracia, la proximidad programática deja de ser un factor decisivo. En su lugar, cobran fuerza la intensidad de los liderazgos y la capacidad para formar clientelas partidarias sustentadas en un significativo gasto en campañas. Esto es, al menos, lo que sostengo para el caso de Chile.

El artículo se divide en tres partes. La primera describe los estudios de opinión aplicados a los congresistas chilenos en 2010 y 2011-2012 por el Observatorio Político-Electoral de la Universidad Diego Portales (UDP). La segunda tiene como objetivo relacionar la congruencia programática con la institucionalización de los sistemas de partidos y con la calidad de la democracia. En la tercera parte se aborda la congruencia programática en Chile considerando el auto posicionamiento de partidos y electores en los ejes eje izquierda-derecha, estado-mercado y liberal-conservador. En esta misma sección, se muestra cuán proclives al régimen democrático son los representantes y los votantes de cada coalición, comparando además las percepciones de congresistas y electores sobre la sociedad chilena. Finalmente, se exponen algunas conclusiones.

\section{Encuesta a ciudadanos y congresistas}

En 2010 y 2011-2012 el Observatorio Político-Electoral del Instituto de Investigación en Ciencias Sociales (ICSO) de la Universidad Diego Portales de Chile realizó dos estudios sobre congruencia programática entre representantes y votantes. En 2010 se logró entrevistar a todos los diputados, cuestión inédita en este tipo de investigaciones. En 2011-2012, en suma, se entrevistó al total de diputados y senadores. En total, se entrevistó a 158 personas (120 diputados y 38 senadores). El trabajo de campo del estudio de 2011-2012 se desarrolló entre julio de 2011 y enero de 2012. El objetivo del proyecto consistió en comparar las opiniones de los congresistas y de la ciudadanía respecto a temas de democracia, política, ciudadanía y discriminación. Al igual que en el estudio de 2010, se aplicó un cuestionario idéntico a ciudadanos y congresistas. La tabla 1 muestra la distribución por partido y coalición de acuerdo a los datos del estudio 2011-2012, al igual que el número de identificados de acuerdo a la Encuesta Nacional de la Universidad Diego Portales de 2011. 
Tabla 1. Diputados, senadores y votantes por partido y coalición

\begin{tabular}{|c|c|c|c|c|c|}
\hline Coalición & Partido & Diputados & Senadores & Total congresistas & Votantes \\
\hline \multirow[t]{3}{*}{ Alianza } & UDI & 39 & 8 & 47 & 36 \\
\hline & RN & 17 & 8 & 25 & 73 \\
\hline & Subtotal & 56 & 16 & 72 & 109 \\
\hline \multirow[t]{5}{*}{ Concertación } & PDC & 19 & 9 & 28 & 83 \\
\hline & PPD & 18 & 4 & 22 & 63 \\
\hline & PS & 11 & 5 & 16 & 76 \\
\hline & PRSD & 5 & 1 & 6 & 5 \\
\hline & Subtotal & 53 & 19 & 72 & 227 \\
\hline \multirow[t]{7}{*}{ Otros } & PC & 3 & 0 & 3 & 47 \\
\hline & PRI & 2 & 0 & 2 & 9 \\
\hline & MAS & 0 & 1 & 1 & - \\
\hline & $\mathrm{PH}$ & 0 & 0 & 0 & 15 \\
\hline & PRO & 0 & 0 & 0 & 4 \\
\hline & Independientes & 6 & 2 & 8 & 891 \\
\hline & Total & 120 & 38 & 158 & 1302 \\
\hline
\end{tabular}

Fuente: Elaboración propia con datos de la encuesta a congresistas ICSO-UDP 2011-2012.

PC: Partido Comunista

PRI: Partido Regionalista de los Independientes

MAS: Movimiento Amplitud Social

PH: Partido Humanista

PRO: Partido Progresista

La bancada de diputados más numerosa es la de la UDI con treinta y nueve escaños. Su socio de pacto es Renovación Nacional (RN) que tiene diecisiete representantes. La Concertación, en tanto, y tomando en cuenta que fue la coalición gobernante entre 1990 y 2010, cuenta con diecinueve diputados del Partido Demócrata Cristiano (PDC), dieciocho del Partido por la Democracia (PPD), once del Partido Socialista (PS), y cinco del Partido Radical Social Demócrata (PRSD). La última columna indica el número de encuestados que se identifica con cada uno de los partidos. 


\section{Congruencia programática}

Se supone que el vínculo programático entre partidos y electores es más fuerte en aquellos países donde los votantes tienen opiniones similares a las de sus representantes. Al existir este tipo de relación, los votantes apoyan o desechan partidos de acuerdo a su capacidad para cumplir con los programas de gobierno. Así, gobiernos de partido responsable tienden a generar apoyos ciudadanos que los confirman en el poder (Ver Adams, 2001; Luna, 2007; Kitschelt et al., 2010). ${ }^{1}$

Es distinto cuando partidos aparentemente programáticos aplican políticas diferentes a las de sus programas de campaña; los votantes se sienten engañados, pues apoyaron a un partido que ofertó un tipo de política y terminó aplicando otra. En este lance sucede lo que Stokes (2001) define como policy switch. Los casos más emblemáticos son los de Fujimori en Perú y Menem en Argentina ( Morgan, 2003; Weyland, 2004). ${ }^{2}$ Incluso, los policy switch se han dado en sistemas de partidos reconocidamente institucionalizados como Venezuela y Costa Rica, por lo tanto, los policy switch no son privativos de democracias débiles o de sistemas de partidos volátiles, siendo extensivo a democracias con mayores niveles de consolidación (Stokes, 2001).

La incongruencia entre votantes y partidos puede originar fuertes corrientes de desafección, lo que contribuye al colapso del sistema de partidos vigente y a la generación de nuevos realineamientos electorales. Todo esto puede ir acompañado de una profunda crisis de representación ${ }^{3}$. Tal es el caso de Venezuela (Morgan, 2007). En cambio, en países donde prima una vinculación no programática entre partidos y electores, son las prácticas clientelares las que definen la relación entre representantes y representados. En este caso, no importa tanto si el partido cumplió o no con el programa que ofertó durante la campaña. Lo relevante es la capacidad del partido para sostener el vínculo clientelar basado en el intercambio de favores por votos. Estos sistemas parecen ser más inestables y con bajas dosis de accountability o rendición de cuentas por parte de los ciudadanos

1 Véase, además, el concepto de representación por mandato y cesión en Coppedge 2001: 2, nota de pie 2.; (Kitschelt et al., 1999: 80-82), (Przeworski 1997: 2), (Samuels y Shugart 2003: 34-35). Un buen trabajo sobre la conceptualización de congruencia es el de Golder y Stramski (2010). Sobre la congruencia en sistemas de partidos europeos, ver Belchior (2010).

2 Para una revisión más completa de la vinculación entre partidos y electores, véase Miller y Stokes (1963), Converse y Pierce (1986), Dalton (1985), Jacobs y Shapiro (2002).

3 Sobre la crisis de representación, véase Hagopian (1998), Mainwaring, Bejarano y Pizarro (2006), Roberts (2002) y Torcal (2001). 
hacia los gobernantes y entre las instituciones que se encargan de fiscalizar los actos de gobierno (O'Donnell, 1997).

En consecuencia, la vinculación programática entre partidos y electores funciona como una especie de barrera de contención para líderes populistas con discutibles credenciales democráticas. Los sistemas con altos niveles de estructuración programática de preferencias electorales tienden a ser más estables (Luna y Zechmeister, 2010). Como los votantes ejercen accountability sobre los partidos y éstos saben que de no cumplir su programa de gobierno corren el riesgo de perder la próxima elección, entonces seguramente ningún partido de gobierno se atreverá a engañar a sus propios votantes. En los sistemas de vinculación programática, adicionalmente, existen oposiciones creíbles capaces de gobernar. Por tanto, los votantes siempre tienen al menos dos opciones viables, lo que genera sistemas de partidos más competitivos y con mayor participación.

En este contexto, Chile ha sido sistemáticamente clasificado como un país con altos niveles de estructuración programática de las preferencias (Mainwaring y Torcal, 2005; Luna y Zechmeister, 2005 y 2010). ${ }^{4}$ Sobre la base de las encuestas aplicadas por el equipo de Manuel Alcántara en la Universidad de Salamanca, ${ }^{5}$ se concluye que los votantes chilenos tienen percepciones similares a las de sus congresistas respecto a temas políticos, económicos, valóricos y sociales. No obstante, el estudio del Observatorio Político-Electoral de la UDP de 2010 desmitificó parcialmente esta tesis. Si bien la congruencia programática es fuerte en Chile, ésta se origina fundamentalmente entre votantes y congresistas de la Concertación (coalición que gobernó Chile entre 1990 y 2010). En dicho estudio se advierte sobre la distancia programática que existía entre votantes y congresistas de la Alianza o Coalición por el Cambio (coalición de centro-derecha). Mientras los electores de la Alianza se mostraban más liberales en temas valóricos como el aborto, divorcio y eutanasia, los diputados de la Alianza eran mucho más conservadores.

Como se señaló anteriormente, Chile es un caso muy particular en América Latina, es considerado como uno de los países con mayor calidad de la democracia y al mismo tiempo con altos niveles de desafección partidaria y hacia las instituciones. Las gráficas 1 y 2 muestran la posición de Chile respecto a tres variables centrales: calidad de la democracia, institucionalización y vinculación programática. La gráfica 1 muestra que

\footnotetext{
Véase más específicamente el trabajo de Siavelis (2009).

Véase http://americo.usal.es/oir/elites/Chilecues.htm Alcántara, (2006) Luna (2008 y 2010) y Morales y Navia (2010).
} 
efectivamente y tal como sostienen Mainwaring y Torcal (2005), los países con sistemas de partidos institucionalizados generalmente favorecen mejores niveles de calidad democrática. Estos sistemas se caracterizan por una baja volatilidad electoral y un alto raigambre social de los partidos. Chile aparece en el grupo avanzado junto a Uruguay y Costa Rica. No obstante, y como muestra la gráfica 2, el grado de vinculación programática no se relaciona linealmente con los niveles de calidad de la democracia. Para el cálculo de la vinculación programática se sigue a Mainwaring y Torcal (2005). Se aplica una regresión logit multinominal que ocupa como variable dependiente la identificación (o intención de voto) con los partidos más grandes, y como variable independiente la escala política izquierda-derecha. La regresión arroja un valor de Pseudo R cuadrado, si ese valor está más cerca de 1, la vinculación programática será mayor. En otras palabras, si el eje izquierda-derecha explica robustamente la identificación o intención de voto por los partidos (discriminando entre ellos), implica que los votantes tienen opciones electorales más cristalizadas. La correlación entre vinculación programática y calidad es muy cercana a 0 . Chile y Costa Rica, ambos con altos niveles de calidad de la democracia en el contexto latinoamericano, tienen grados de vinculación programática similares a los de Perú o Venezuela mientras que en El Salvador, el país con el mayor grado de vinculación programática del continente, presenta una baja calidad de

\section{Gráfica 1. Institucionalización y calidad de la democracia en América Latina}

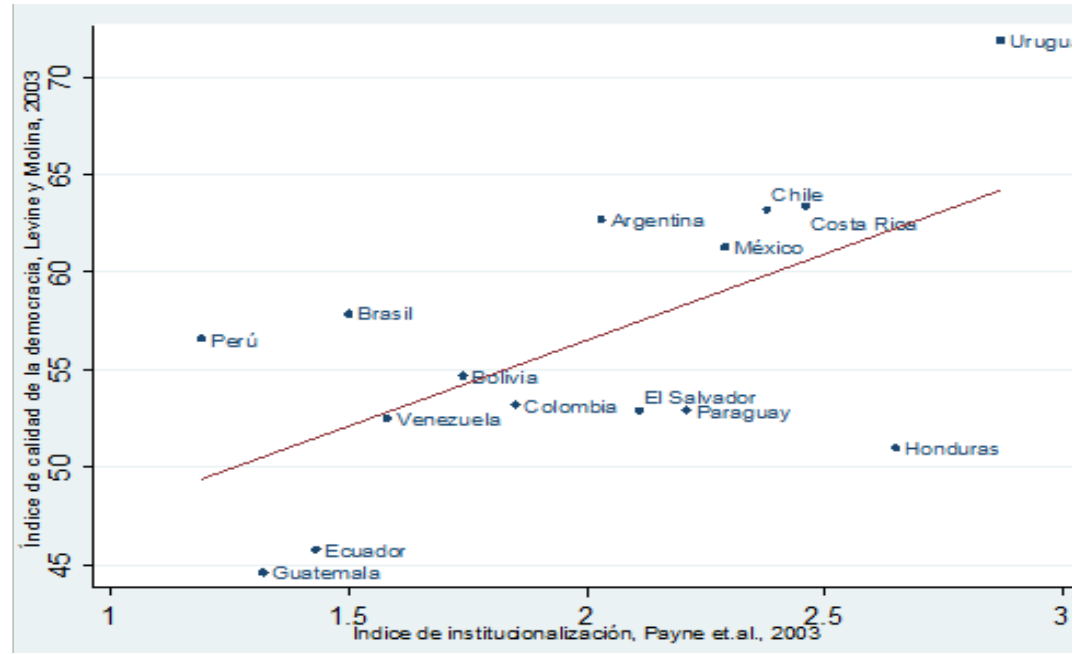

Fuente: Elaboración propia con datos de Levine y Molina (2007) y Payne et al. (2003). 
la democracia. En resumen, no existe, aparentemente, una relación lineal entre el nivel de vinculación programática, el grado de institucionalización de los sistemas de partidos y la calidad de la democracia.

\section{Gráfica 2. Vinculación programática y calidad de la democracia en América Latina}

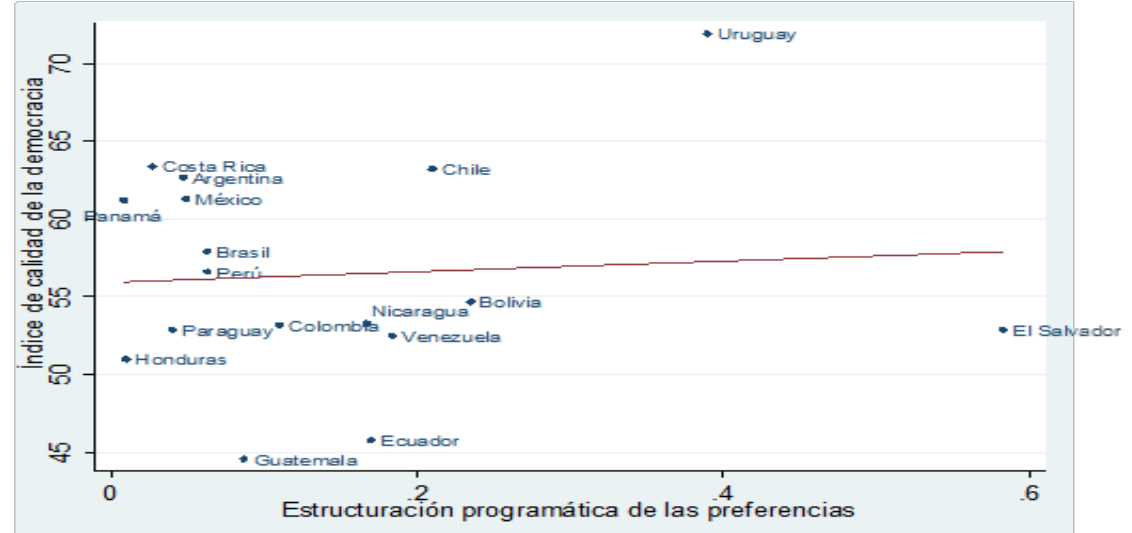

Fuente: Elaboración propia con datos de Levine y Molina (2007) y los resultados del estudio LAPOP $2010 .^{6}$

Existen casos de países con alto grado de institucionalización partidaria y bajísimos niveles de vinculación programática, tal es el caso de Honduras. También hay sistemas de partidos escasamente volátiles, pero poco institucionalizados como Paraguay. Finalmente, existen sistemas de partidos escasamente volátiles, supuestamente institucionalizados, con alta calidad de la democracia y con modestos niveles de vinculación programática entre partidos y electores, este es el caso de Chile. Cabe aclarar, eso sí, que el grado de vinculación programática aumenta si en lugar de partidos se considera a las coaliciones. La tabla 2 sintetiza estos resultados. Si bien Chile aparece segundo tras Honduras al medir volatilidad, ocupa los últimos lugares en identificación partidaria o raigambre social de los partidos. De acuerdo al estudio LAPOP de 2008, sólo uno de cada cinco chilenos se identifica con partidos. Estas cifras, según el mismo estudio para 2010, se aproxima al 11 por ciento, lo que ubica a Chile en el último lugar del ranking. Esta combinación entre baja volatilidad y baja identificación es precisamente, lo que caracteriza a un sistema de partidos hidropónico.

6 LAPOP, Proyecto de Opinión Pública de América Latina de la Universidad de Vanderbilt. Véase http:// lapop.ccp.ucr.ac.cr/ 
Tabla 2. Volatilidad, calidad de la democracia, identificación e institucionalización partidaria en América Latina

\begin{tabular}{|c|c|c|c|c|}
\hline Pais & $\begin{array}{l}\text { Índice de } \\
\text { volatilidad }\end{array}$ & $\begin{array}{c}\text { Índice de calidad de } \\
\text { la democracia }\end{array}$ & $\begin{array}{c}\text { Porcentaje de identifi- } \\
\text { cación partidaria }\end{array}$ & $\begin{array}{c}\text { Índice de } \\
\text { institucionalización }\end{array}$ \\
\hline Honduras & 6.1 & 51.0 & 48.7 & 2.65 \\
\hline Chile & 7.3 & 63.2 & 21.4 & 2.38 \\
\hline El Salvador & 12.9 & 52.9 & 49.9 & 2.11 \\
\hline Brasil & 14.3 & 57.9 & 25.2 & 1.5 \\
\hline Nicaragua & 15.3 & 53.3 & 40.3 & s.d. \\
\hline México & 25.9 & 61.3 & 32.2 & 2.29 \\
\hline Uruguay & 26.7 & 71.9 & 50.4 & 2.87 \\
\hline Costa Rica & 27.6 & 63.4 & 30.3 & 2.46 \\
\hline Argentina & 27.9 & 62.7 & 24.8 & 2.03 \\
\hline Panamá & 31.0 & 61.2 & 32.1 & s.d. \\
\hline Paraguay & 35.8 & 52.9 & 59 & 2.21 \\
\hline Perú & 44.7 & 56.6 & 19.2 & 1.19 \\
\hline Guatemala & 45.5 & 44.6 & 15.9 & 1.32 \\
\hline Colombia & 47.3 & 53.2 & 29.2 & 1.85 \\
\hline Venezuela & 49.2 & 52.5 & 32.7 & 1.58 \\
\hline Bolivia & 64.1 & 54.7 & 29 & 1.74 \\
\hline Ecuador & 71.8 & 45.8 & 18.9 & 1.43 \\
\hline
\end{tabular}

Fuente: Elaboración propia con datos de la base histórica de volatilidad de Mainwaring et al. (2008), Levine y Molina (2007), LAPOP 2008 y Payne et al. (2003).

Lo anterior se refuerza con los datos de la tabla 3, donde se muestra un modelo de regresión logit multinominal. La variable dependiente es la identificación con partidos, se incluyen los seis más grandes. Las variables independientes corresponden a los cuatro ejes clásicos de división partidaria: izquierda-derecha, estado-mercado, liberal-conservador, urbanorural. ${ }^{7}$ Estas variables no están estrechamente relacionadas, por lo que no

7 Para el eje ideológico se utiliza la pregunta de auto posicionamiento en la escala izquierda-derecha, siendo 1 "muy de izquierda" y 10 "muy de derecha". Para el eje estado-mercado se seleccionó la siguiente pregunta. “Ahora, vamos a usar una tarjeta similar, pero el punto 1 representa 'muy en desacuerdo' y el punto 7 representa "muy de acuerdo". Un número entre el 1 y el 7, representa un puntaje intermedio. Yo le voy a leer varias afirmaciones y quisiera que me diga hasta qué punto está de acuerdo o en desacuerdo con esas afirmaciones. El Estado (se nombra país), en lugar del sector privado, debería ser el dueño de las empresas e industrias más importantes del país. ¿Hasta qué punto está de acuerdo o en desacuerdo con esta frase?". Si bien puede ser discutible que esta pregunta por sí misma capture la tensión 
generan problemas de multicolinealidad dentro del modelo. En otras palabras, miden dimensiones distintas. La categoría de referencia es el "Partido

Socialista". Lo que muestra el modelo es que la principal variable que discrimina entre los votantes de cada partido es el eje izquierda-derecha. En el resto no se observan mayores diferencias. Esto contrasta con otros países de América Latina donde hay diferencias según el eje liberal-conservador como Uruguay o en el eje urbano-rural como El Salvador.

\section{Tabla 3. Modelo de regresión multinomial para la identificación partidaria en}

Chile

\begin{tabular}{|c|c|c|c|}
\hline \multicolumn{4}{|l|}{ cnlle } \\
\hline & & Beta & Sig \\
\hline \multirow{4}{*}{$P P D$} & Eje izquierda-derecha & 0.327 & 0.005 \\
\hline & Eje mercado-estado & 0.135 & 0.267 \\
\hline & Eje conservador-liberal & 0.352 & 0.062 \\
\hline & Eje urbano-rural & -0.105 & 0.908 \\
\hline \multirow{4}{*}{$P D C$} & Eje izquierda-derecha & 0.365 & 0.001 \\
\hline & Eje mercado-estado & 0.089 & 0.429 \\
\hline & Eje conservador-liberal & -0.207 & 0.188 \\
\hline & Eje urbano-rural & 1.704 & 0.009 \\
\hline \multirow{4}{*}{$P C$} & Eje izquierda-derecha & -0.067 & 0.664 \\
\hline & Eje mercado-estado & -0.022 & 0.875 \\
\hline & Eje conservador-liberal & 0.076 & 0.723 \\
\hline & Eje urbano-rural & 0.112 & 0.923 \\
\hline \multirow{4}{*}{$R N$} & Eje izquierda-derecha & 1.109 & 0.000 \\
\hline & Eje mercado-estado & -0.131 & 0.251 \\
\hline & Eje conservador-liberal & -0.030 & 0.866 \\
\hline & Eje urbano-rural & 0.747 & 0.348 \\
\hline \multirow{5}{*}{$U D I$} & Eje izquierda-derecha & 1.052 & 0.000 \\
\hline & Eje mercado -estado & -0.076 & 0.530 \\
\hline & Eje conservador-liberal & -0.001 & 0.995 \\
\hline & Eje urbano-rural & -0.302 & 0.762 \\
\hline & $\begin{array}{l}\text { Pseudo R cuadrado } \\
\mathrm{N}\end{array}$ & $\begin{array}{l}0.21 \\
250\end{array}$ & \\
\hline
\end{tabular}

*Base de comparación: Partido Socialista.

Fuente: Elaboración propia con datos de LAPOP 2008.

estado-mercado, al utilizar otra pregunta de la misma batería de LAPOP, los resultados son más o menos similares. La pregunta coloca a los encuestados en un dilema respecto a que el estado o los privados se hagan cargo de las empresas más importantes del país, lo que permite distinguir a encuestados estatistas y libre mercadistas. Para el eje liberal-conservador se utilizó la pregunta sobre asistencia a oficios religiosos. Finalmente, el eje urbano-rural se mide de acuerdo a la clasificación que realiza la misma encuesta. 


\section{Partidos y votantes en Chile: el eje izquierda-derecha}

El eje izquierda-derecha permite distinguir y ubicar a partidos y electores. Es el principal predictor de la intención de voto y facilita el ordenamiento de las preferencias. En el caso de Chile, este eje permite distinguir claramente entre los partidos y coaliciones (Navia, 2005; Morales, 2012b. Desde las elecciones inaugurales de la democracia en 1989, han competido dos grandes coaliciones que copan alrededor del 85 por ciento de los votos. Esto se debe en gran medida al efecto del sistema electoral binominal para elegir congresistas. Como se eligen dos representantes por distrito (diputados) y circunscripción (senadores), entonces las dos coaliciones más grandes son las que tienen mayor probabilidad de obtener representación. Generalmente, cada coalición obtiene un escaño por distrito.

El eje izquierda-derecha, además, sirvió como telón de fondo para estructurar las preferencias de los electores en la división política entre partidarios y opositores al régimen de Pinochet (1973-1989). Este eje explica, en parte, la estabilidad en la votación de las dos principales coaliciones. Como muestra la gráfica 3, la Concertación predominó ampliamente hasta las elecciones de diputados en 2001. Retomó ventaja en los comicios de 2005, pero la correlación de fuerzas volvió a estrecharse en 2009. Como señalé en el párrafo anterior, hay poco espacio para los independientes o terceras fuerzas producto del sistema electoral binominal.

\section{Gráfica 3. Porcentaje de votos Concertación y Alianza 1989-2009, elecciones de diputados}

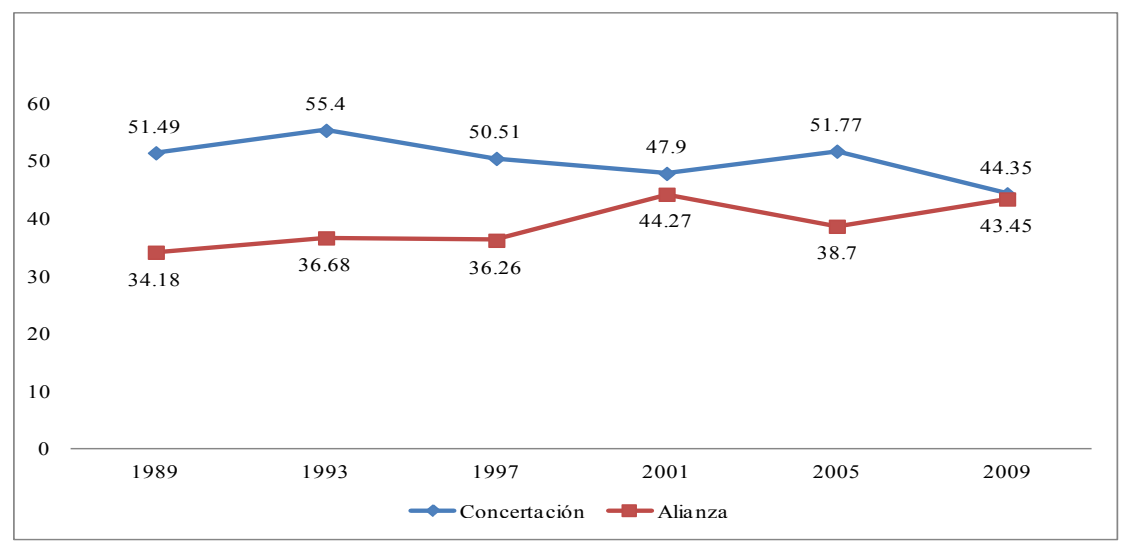

Fuente: Elaboración propia con datos de www.elecciones.gov.cl 
La estabilidad electoral de Chile no debe ser confundida con la alta identificación partidaria o con la significativa congruencia entre partidos y votantes. La estabilidad electoral puede esconder perfectamente la desafección partidaria y la distancia entre partidos y votantes. A nivel agregado es posible encontrar estabilidad incluso en los patrones de votación de los partidos, aunque esto no implica necesariamente que los partidos tengan una fuerte raigambre social o que sus votantes piensen de manera similar a su élite. Lo que indican los datos que comparan a representantes y votantes reafirman esta idea. Como muestra la gráfica 4 y de acuerdo con los datos de nuestro estudio de 2011, se advierte una mayor polarización de la élite de congresistas en comparación con la distribución de los electores. La gráfica está construida considerando la porción de encuestados (ciudadanos y diputados) que se auto-ubica en los casilleros de la escala izquierda-derecha que van de 1 (muy de izquierda) a 10 (muy de derecha). Mientras los congresistas copan las posiciones más genuinas de izquierda y derecha, los votantes prefieren valores orientados hacia el centro de la distribución. A esto se debe agregar que el 31.1 por ciento de los ciudadanos no se identifica con ningún peldaño de la escala, cifra que es de cero en los congresistas.

Este desbalance entre las opiniones de votantes y representantes puede obedecer a las características del sistema electoral binominal. Existe una incipiente literatura que estudia el efecto de los sistemas electorales sobre la congruencia programática entre partidos y electores (Powell, 2009; Budge y McDonald, 2007). El consenso apunta a que los sistemas proporcionales generan mayores dosis de congruencia programática que los sistemas mayoritarios. Esto es porque los sistemas proporcionales dan cabida a casi todas las expresiones ciudadanas, mientras que los mayoritarios reducen a dos las opciones disponibles. No obstante, han surgido cuestionamientos a esta tesis, el trabajo de Golder y Stramski (2010) es un buen ejemplo. Esta discusión es conocida como ideological congruence controversy, cuyo principal exponente es Powell (2009).

El sistema electoral binominal, por su baja magnitud de distrito y por los incentivos que otorga a los candidatos, empuja a partidos y coaliciones a buscar electores en los extremos de la distribución. Teóricamente, los candidatos garantizan su triunfo obteniendo un tercio de los votos. El incentivo, por tanto, se utiliza para buscar a los electores más leales y que frecuentemente se encuentran en dichos extremos. No hay incentivos para avanzar hacia votantes de centro. En consecuencia, el sistema binominal favorece la competencia centrífuga y no la competencia centrípeta (Magar 
et.al., 1998; Navia, 2005). Por tanto, esperables de esperarse que los legisladores tengan opiniones políticas más extremas que los ciudadanos.

\section{Gráfica 4. Autoposicionamiento de congresistas y ciudadanía en el eje izquierda-derecha}

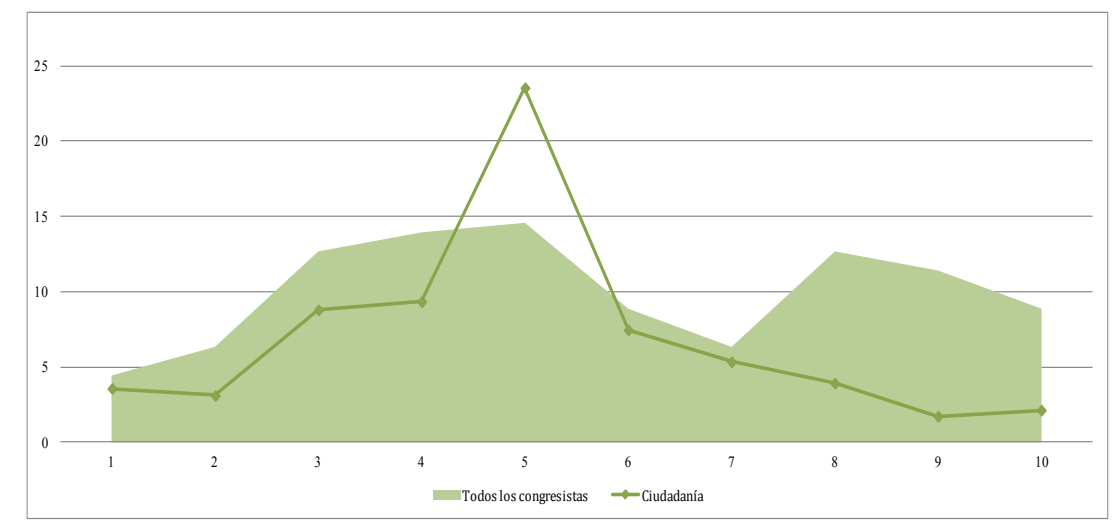

Fuente: Elaboración propia con datos de la encuesta nacional ICSO-UDP 2011 y de la encuesta a congresistas ICSO-UDP 2011-2012. La pregunta que se formula tanto para la ciudadanía como para los congresistas es la siguiente: "Utilizando una escala de 1 a 10, donde 1 representa más de izquierda y 10 más de derecha, ¿en qué posición se ubicaría usted?".

Si bien el autoposicionamiento de diputados y senadores del mismo partido es similar, no deja de llamar la atención que, por ejemplo, los senadores de la UDI estén más a la derecha que sus propios diputados y que los senadores del PS y del PPD estén más a la izquierda que sus diputados. Supuestamente, los senadores son representantes más moderados que en lugar de buscar la polarización, persiguen los acuerdos y consensos básicos. Probablemente esto se deba a que en el caso de la UDI, su bancada de senadores está compuesta por la dirigencia antigua del partido y que, seguramente, defiende la posición política original de la colectividad. En dicho partido destacan Hernán Larraín, Juan Antonio Coloma, Jovino Novoa, Jaime Orpis y Víctor Pérez. En el caso del PS y del PPD sucede algo más o menos similar, destacando los casos de Camilo Escalona, Guido Girardi, Isabel Allende y Juan Pablo Letelier.

El partido más congruente con la ciudadanía en la escala política es el PDC (véase tabla 4). No obstante, y a pesar de su cercanía con lo que piensan los electores, es el partido que ha perdido más votos desde el retorno de la democracia. De esto se infiere que la proximidad con los votantes no es condición suficiente (tal vez ni siquiera necesaria) para lograr el éxito en las urnas. A esto se deben añadir dosis razonables de intensidad política (Rabinowitz y Macdonald, 1989; Iversen, 1994), cuyo principal indicador es 
el número de líderes con que cuenta el partido y que son reconocidos por la ciudadanía. De acuerdo con las encuestas del CEP, el PDC tenía entre seis y ocho líderes dentro de los diez personajes públicos mejor evaluados por la ciudadanía a mediados y finales de los noventa. En la última encuesta de 2011, no obstante, esa cifra había descendido a uno, la senadora Soledad Alvear. Por lo tanto, no es extraño que los congresistas del PDC se inclinen por opciones políticas similares a las de la ciudadanía, aunque esto no implique preferencia en las urnas.

Tabla 4. Promedio en escala política de las bancadas parlamentarias y simpatizantes por partido

\begin{tabular}{|l|l|l|l|c|c|c|c|}
\hline Coalición & Partido & Votantes & Diputados & Senadores & $\begin{array}{c}\text { Promedio } \\
\text { general } \\
\text { congresistas }\end{array}$ & $\begin{array}{c}\text { Diferencia } \\
\text { congresistas } \\
\text { y sus } \\
\text { votantes }\end{array}$ & $\begin{array}{c}\text { Diferencia } \\
\text { congresistas } \\
\text { y promedio } \\
\text { nacional de } \\
\text { votantes }\end{array}$ \\
\hline Alianza & UDI & 7.65 & 8.33 & 9.25 & 8.49 & 0.84 & 3.53 \\
\hline & $R N$ & 7.63 & 7.35 & 7.38 & 7.36 & -0.27 & 2.4 \\
\hline Concertación & PDC & 4.61 & 4.32 & 4.78 & 4.46 & -0.15 & -0.5 \\
\hline & PRSD & 4.51 & 3.60 & 3.00 & 3.50 & -1.01 & -1.46 \\
\hline & PPD & 4.09 & 3.89 & 3.00 & 3.73 & -0.36 & -1.23 \\
\hline & PS & 3.42 & 2.55 & 2.00 & 2.37 & -1.05 & -2.59 \\
\hline & PC & 3.04 & 1.00 & - & - & - & - \\
\hline & PRI & - & 4.50 & - & - & - & - \\
\hline & Indep & 4.97 & 4.83 & 6.50 & 5.25 & 0.28 & 0.29 \\
\hline & Total & 4.96 & 5.74 & 5.71 & 5.73 & 0.77 & 0.77 \\
\hline
\end{tabular}

Fuente: Elaboración propia con datos de la encuesta nacional ICSO-UDP 2011 y de la encuesta a congresistas ICSO-UDP 2011-2012. Para el caso de los independientes en la columna "votantes" se consideró a aquellos que no manifestaron adhesión a ningún partido.

Finalmente, la tabla 5 muestra el grado de cohesión de cada bancada de acuerdo al eje izquierda-derecha. Se calcula la desviación estándar con el fin de observar cuán concentradas están las opiniones respecto a la media de cada grupo, ésta se segmenta entre senadores y diputados y, al mismo tiempo, se compara con la dispersión de los votantes. Ciertamente, el tamaño de los grupos difiere según partido y bancada. Se advierte que las bancadas de senadores tienden a ser más cohesionadas que las de diputados, esto es más evidente en los partidos de derecha. A pesar de que los senadores tienen un posicionamiento más extremo en la escala, sus opiniones son más o menos homogéneas. Lo mismo ocurre con el PDC, su bancada de senadores es mucho más homogénea que la de diputados, donde se observan mayores niveles de dispersión. En el PPD y especialmente en el PS, 
las bancadas de senadores y diputados son más homogéneas, de hecho, los senadores de la bancada PS se posicionan exactamente en el mismo peldaño de la escala política, de ahí que su desvío estándar sea de 0 (valor 2).

Tabla 5. Desviación estándar en la escala política, votantes y partidos

\begin{tabular}{|l|c|c|c|}
\hline Partido & Votantes & Diputados & Senadores \\
\hline UDI & 1.44 & 1.51 & 0.71 \\
\hline RN & 1.74 & 1.37 & 1.06 \\
\hline PRI & 2.04 & 0.71 & - \\
\hline PDC & 1.65 & 1.29 & 0.44 \\
\hline PPD & 1.64 & 0.90 & 0.82 \\
\hline PS & 1.34 & 0.93 & 0.00 \\
\hline PC & 2.15 & 0.00 & - \\
\hline PRSD & 2.03 & 0.55 & - \\
\hline Independientes & 1.63 & 2.93 & 0.71 \\
\hline Total & 1.99 & 2.64 & 2.65 \\
\hline
\end{tabular}

Fuente: Elaboración propia con datos de la encuesta nacional ICSO-UDP 2011 y de la encuesta a congresistas ICSO-UDP 2011-2012.

\section{Congruencia programática: política, economía, valores}

No deja de sorprender que en un sistema aparentemente institucionalizado y con una razonable estructuración programática de las preferencias, el partido más congruente con la ciudadanía baje significativamente su cantidad de votos y que el partido más incongruente la aumente de manera considerable (véase gráfica 5). Es lo que sucede con el PDC, que ha disminuido su votación de un 26 por ciento a un 14 por ciento desde 1989 a 2009. La UDI, en tanto, ha subido del 9.8 por ciento al 23 por ciento. Esto retrata un sistema de partidos con dudosas credenciales de institucionalización. Como apunté con anterioridad, la estabilidad electoral no implica necesariamente vinculación programática ni institucionalización de un sistema de partidos. Dicho sistema puede ser escasamente volátil, aunque involucre bajos niveles de identificación y altas dosis de incongruencia entre partidos y electores. La explicación respecto a la estabilidad en las votaciones por coalición pasa fundamentalmente por el tipo de sistema electoral. Como señalé, lo más probable es que en cada distrito se elija un representante de cada coalición. 


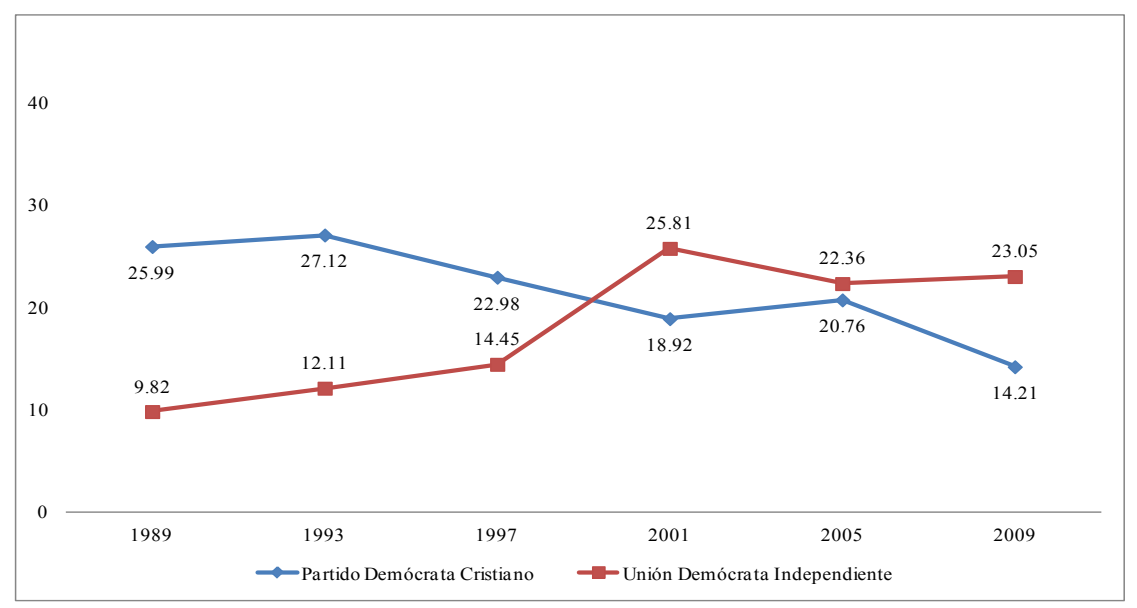

Fuente: Elaboración propia con datos de www.elecciones.gov.cl

No obstante, el sistema electoral no explica los cambios en las votaciones por partido. El sistema binominal se aplica desde 1990 y sin modificación alguna, por lo que, más bien, es una constante que no puede explicar las variaciones o cambios en los resultados electorales. Existen otras razones, por un lado, se encuentra el debilitamiento del eje autoritarismo-democracia que ordenó las preferencias de los electores en la década de los noventa. Por otro, y asociado a lo anterior, está la emergencia de electores menos renuentes a atravesar las antiguas barreras ideológicas y más permeables a aceptar el clientelismo como una forma de relación política. Esto ha dado paso a una mayor relevancia del dinero en las campañas (Morales y Piñeiro, 2010). Por ejemplo, si para las elecciones de diputados de 2009 la UDI gastó cerca de 9 millones de dólares, el PDC gastó menos de la mitad, o sea 4 millones. El gasto por voto recibido fue de 6 dólares para la UDI y de 4.3 dólares para el PDC (véase gráfica 6). 


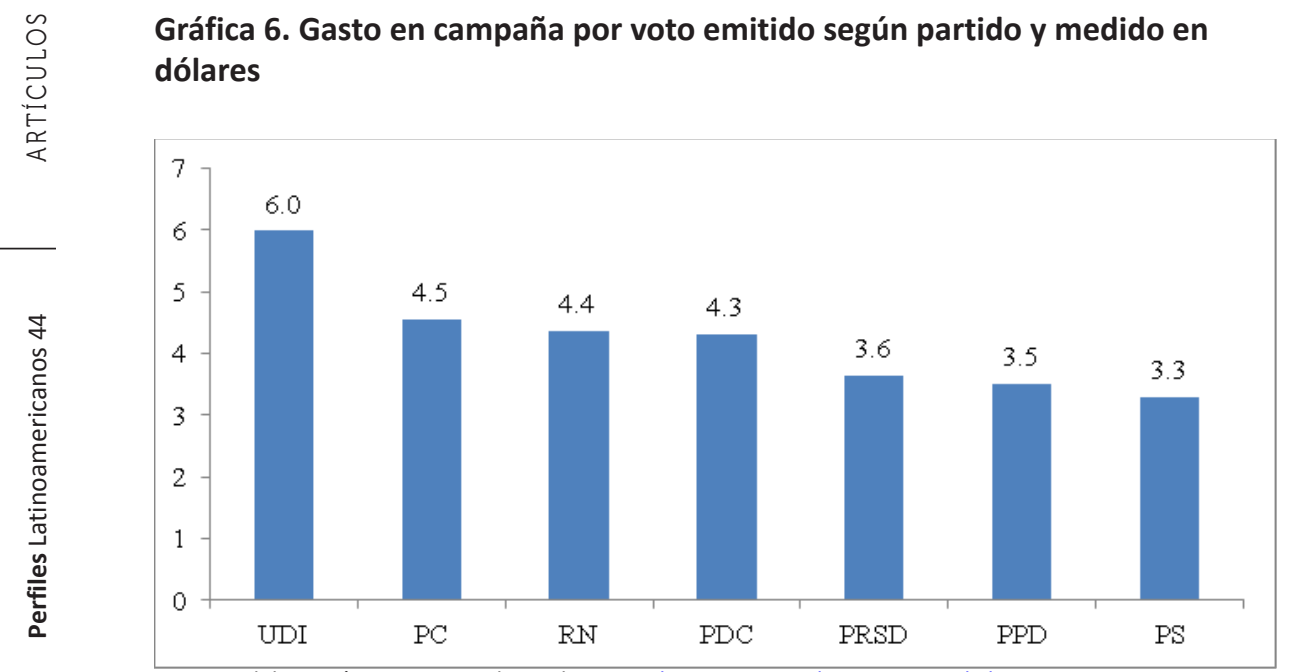

Fuente: Elaboración propia con datos de www.elecciones.gov.cl y www.servel.cl

Estas hipótesis tienen asidero a partir de los datos de nuestro estudio de 2010. Las gráficas 7 y 8 muestran que, efectivamente, la élite de congresistas de la UDI se encuentra significativamente alejada de lo que piensan los chilenos y sus propios votantes tanto en cuestiones económicas (tensión estado-mercado) como en cuestiones valóricas, que en este caso represento con el porcentaje de apoyo al aborto terapéutico. Ambos ejes, que pueden definirse a partir de una escala liberal-conservador en materias económicas y valóricas, son cruzados con el eje izquierda-derecha.

Cada punto del cuadrante representa a votantes o representantes de cada uno de los partidos políticos. Como se observa, el partido más congruente con la ciudadanía en ambos ejes es el PDC y el más incongruente la UDI. Incluso, en los apoyos al aborto terapéutico, los diputados de la UDI aparecen sustantivamente más distanciados que los de $\mathrm{RN}$, su socio de pacto. 


\section{Gráfica 7. Posicionamiento de diputados (por partido y coalición) y votantes en los ejes izquierda-derecha y mercado-estado}

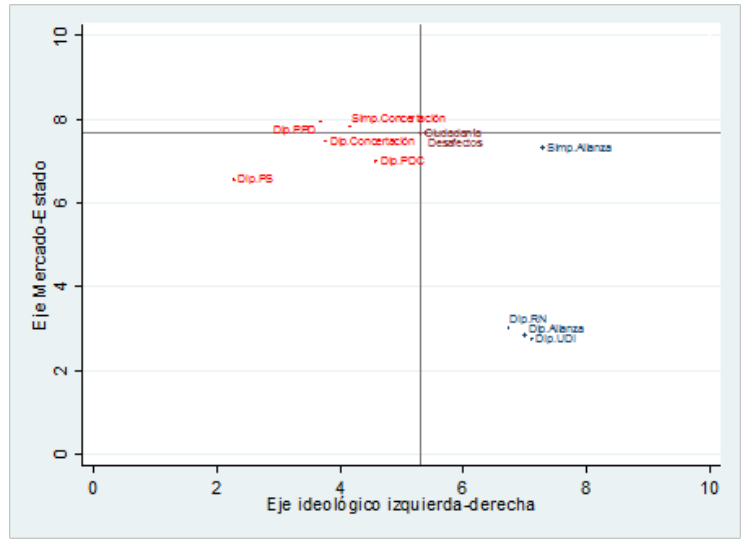

Dip.= diputados, Simp.= simpatizantes, Desafectos= encuestados que no se identifican con algún partido, Ciudadanía= promedio de ambas dimensiones en la Encuesta Nacional UDP. Las rectas que cruzan el gráfico equivalen al promedio de cada eje en la Encuesta Nacional UDP.

Fuente: Elaboración propia con datos de la encuesta nacional ICSO-UDP y de la encuesta parlamentaria ICSO-UDP. La pregunta que se formula tanto para la ciudadanía como para la elite son las siguientes. 1-. "Utilizando una escala de 1 a 10, donde 1 representa más de izquierda y 10 más de derecha, ¿en qué posición se ubicaría usted?". 2-. Y nuevamente utilizando una escala de 1 a 10 donde 1 significa "totalmente en desacuerdo" y 10 "totalmente de acuerdo", ¿cuán de acuerdo o en desacuerdo está usted con las siguientes afirmaciones? "El Estado debiese ser el dueño de las empresas de servicios básicos como luz y agua" (Para ambas preguntas se calcula el promedio en la escala de 1 a 10). 


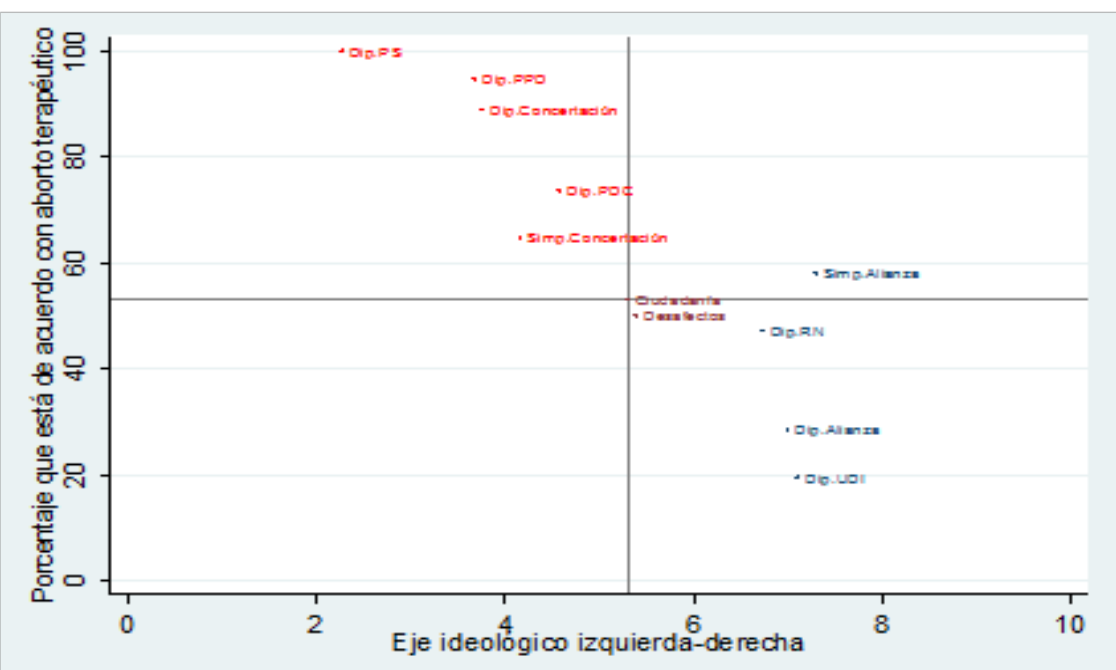

Fuente: Elaboración propia con datos de la encuesta nacional ICSO-UDP y de la encuesta parlamentaria ICSOUDP. Las preguntas que se formulan tanto para la ciudadanía como para la élite son las siguientes: 1-. "Utilizando una escala de 1 a 10, donde 1 representa más de izquierda y 10 más de derecha, ¿en qué posición se ubicaría usted?". 2-. "Para cada una de las siguientes situaciones, ¿está usted de acuerdo o en desacuerdo con que la ley despenalice el aborto si la salud de la madre corre serio peligro por el embarazo?" (Sólo se considera el porcentaje que está de acuerdo).

\section{Democracia y sociedad chilena}

En el estudio de 2011 aplicamos una serie de preguntas sobre tolerancia, discriminación y percepciones de la sociedad chilena. Fuera de encontrar incongruencia en los ejes clásicos de análisis; es decir, izquierda-derecha, estado-mercado y liberal-conservador, en Chile también se observan fuertes diferencias entre la élite y los ciudadanos de acuerdo con los apoyos a la democracia y las percepciones de la sociedad chilena.

Casi dos tercios de los ciudadanos prefieren la democracia a cualquier otra forma de gobierno, cifra que difiere significativamente de la opinión de los congresistas. Los de la Alianza y de la Concertación respaldan la democracia en un 94.4 por ciento y 100 por ciento respectivamente. Las diferencias se producen entre sus votantes. Así, mientras los electores de la Concertación prefieren la democracia en un 73 por ciento, los de la Alianza lo hacen en un 67.8 por ciento. Esta distancia entre representantes y representados no es tan arbitraria, mientras los ciudadanos son críticos y sus juicios están definidos por su situación económica y la satisfacción 
que tengan con el régimen, los congresistas defienden en mayor medida la democracia pues fueron electos fruto del voto popular y sienten el deber de anteponerla a cualquier otra clase de régimen. De tal manera que todos los senadores, independiente del partido político al que adscriban, apoyan la democracia. En cuanto a los diputados, en tanto, sólo 4 de 120 sostienen que en algunas circunstancias, un régimen autoritario puede ser preferible a uno democrático ( 3 de la UDI y 1 de RN).

Esta imagen de la democracia puede obedecer a las percepciones que tienen ciudadanos y representantes sobre la sociedad chilena. Para probar esto, el estudio incluyó una batería de preguntas que tiene como objetivo saber cuán democrática, pacífica, justa, tolerante, racista y clasista es ésta. Colocamos a los encuestados en una escala de 1 a 10 donde el atributo positivo está en los valores bajos de dicha escala. Como muestra la gráfica 9, la ciudadanía tiene evaluaciones más negativas que los congresistas. Sin embargo, al segmentar según coalición, se advierte que los congresistas de la Concertación son claramente más congruentes con la opinión de los ciudadanos. Por el contrario, los de la Alianza son mucho más optimistas y creen en mayor medida que la sociedad chilena es democrática, pacífica, justa, tolerante y carente de racismo y clasismo. Puede ser que tal opinión se deba a que el modelo económico impuesto en la dictadura aún tiene férreos defensores, pues una parte importante de la élite parlamentaria de derecha participó activamente del régimen de Pinochet. Probablemente perciban al modelo como propio y por eso consideran que la sociedad chilena es más virtuosa de lo que generalmente se cree.

\section{Gráfica 9. Percepciones sobre la sociedad chilena (congresistas y votantes)}

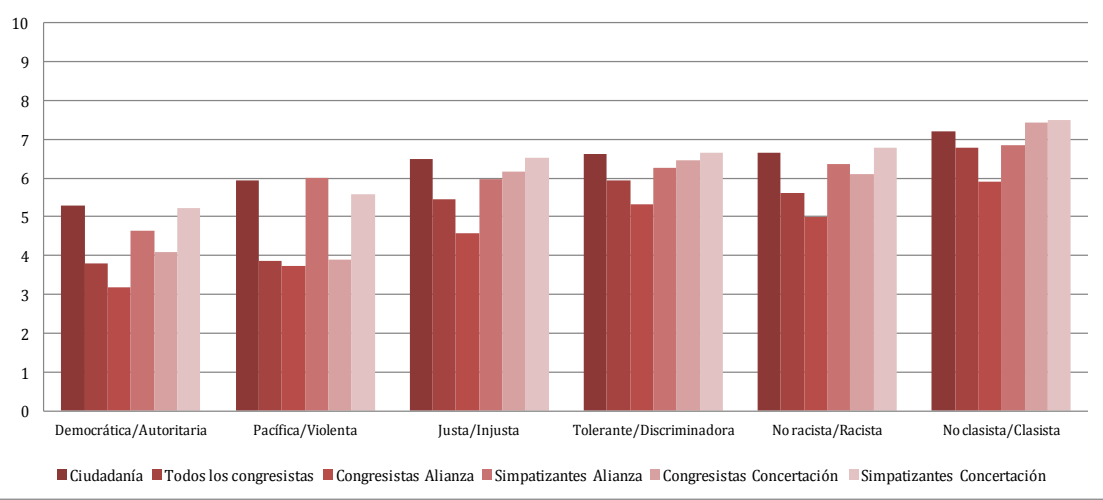

Fuente: Elaboración propia con datos de la encuesta nacional ICSO-UDP 2011 y de la encuesta a congresistas ICSO-UDP 2011-2012. La pregunta que se formula tanto para la ciudadanía como para los congresistas es la siguiente: "De acuerdo con lo que ha visto y en una escala de 1 a 10, la sociedad chilena es...Democrática/ Autoritaria, Pacífica/Violenta, Justa/Injusta, Tolerante/Discriminadora, No racista/Racista, No clasista/Clasista. 
Además, hay fuertes diferencias entre las percepciones de diputados y senadores. Estos últimos son sustancialmente más optimistas y tienen mejores evaluaciones de la sociedad chilena, lo cual aplica tanto para los representantes de la Alianza como para los de la Concertación. La tabla 6 muestra los promedios según bancada de diputados y senadores. Adicionalmente, la gráfica 10 da cuenta de las diferencias promedio entre la media de cada bancada (por partido) y la media nacional agregada en las seis preguntas sobre percepciones de la sociedad chilena. La media nacional es de 6.36. Se restó este valor a todos los promedios de cada diputado o senador para estas seis preguntas. Luego, se calculó una media agregada de esta diferencia según partido y bancada (senadores y diputados). Los valores positivos de esa media agregada indican mejores percepciones sobre la sociedad chilena, en cambio, los valores negativos indican peores percepciones. Por ejemplo, la diferencia entre los diputados del PPD y la media nacional es aproximadamente de 0.5 puntos, esto indica que los diputados del PPD tienen mejores percepciones que la ciudadanía, mientras que los diputados del PC tienen una diferencia de -0.5 puntos, lo que indica que esta bancada tiene peores percepciones sobre la sociedad chilena en comparación con la media nacional.

Tabla 6. Percepciones de la sociedad chilena por parte de diputados y senadores

\begin{tabular}{|c|c|c|c|c|c|c|c|}
\hline Cargo & Partido & $\begin{array}{l}\text { Democrática } \\
\text { /Autoritaria }\end{array}$ & $\begin{array}{l}\text { Pacífica } \\
\text { Niolenta }\end{array}$ & $\begin{array}{l}\text { Justa } \\
\text { /Injusta }\end{array}$ & $\begin{array}{l}\text { Tolerante } \\
\text { /Discriminadora }\end{array}$ & $\begin{array}{l}\text { No racista } \\
\text { /Racista }\end{array}$ & $\begin{array}{l}\text { No clasista } \\
\text { /Clasista }\end{array}$ \\
\hline \multicolumn{8}{|c|}{ Diputado } \\
\hline & UDI & 3.26 & 3.68 & 4.55 & 5.26 & 4.76 & 5.68 \\
\hline & RN & 4.41 & 4.47 & 5.41 & 6.24 & 5.71 & 6.53 \\
\hline & PRI & 6.00 & 4.00 & 5.00 & 6.50 & 5.50 & 7.50 \\
\hline & PDC & 3.74 & 3.21 & 5.79 & 5.89 & 5.68 & 6.53 \\
\hline & PPD & 4.72 & 4.83 & 6.11 & 6.39 & 6.00 & 6.89 \\
\hline & PS & 5.00 & 4.00 & 6.55 & 6.55 & 6.09 & 8.18 \\
\hline & PC & 6.67 & 5.00 & 6.67 & 8.00 & 7.00 & 8.00 \\
\hline & PRSD & 4.00 & 5.00 & 5.80 & 6.60 & 5.80 & 7.40 \\
\hline & Indep & 5.50 & 5.33 & 7.33 & 5.67 & 6.17 & 7.50 \\
\hline & Total & 4.15 & 4.10 & 5.55 & 5.96 & 5.54 & 6.61 \\
\hline
\end{tabular}




\begin{tabular}{|l|l|l|c|c|c|c|c|}
\hline Cargo & Partido & $\begin{array}{c}\text { Democrática } \\
\text { /Autoritaria }\end{array}$ & $\begin{array}{c}\text { Pacífica } \\
\text { /Violenta }\end{array}$ & $\begin{array}{c}\text { Justa } \\
\text { /Injusta }\end{array}$ & $\begin{array}{c}\text { Tolerante } \\
\text { /Discriminadora }\end{array}$ & $\begin{array}{c}\text { No racista } \\
\text { /Racista }\end{array}$ & $\begin{array}{c}\text { No clasista } \\
\text { /Clasista }\end{array}$ \\
\hline Senador & & & & & & & \\
\hline & UDI & 1.38 & 2.50 & 3.13 & 4.25 & 4.63 & 5.38 \\
\hline & RN & 2.00 & 3.50 & 4.25 & 4.75 & 4.88 & 6.25 \\
\hline & PDC & 2.89 & 3.78 & 5.33 & 6.00 & 6.00 & 7.44 \\
\hline & PPD & 3.75 & 3.50 & 7.00 & 6.75 & 7.00 & 9.25 \\
\hline & PS & 3.60 & 2.00 & 7.40 & 8.40 & 7.60 & 9.20 \\
\hline & MAS & 7.00 & 3.00 & 3.00 & 8.00 & 8.00 & 8.00 \\
\hline & PRSD & 5.00 & 5.00 & 10.00 & 9.00 & 7.00 & 10.00 \\
\hline & $\begin{array}{l}\text { Inde- } \\
\text { pendi- } \\
\text { entes }\end{array}$ & 2.00 & 3.00 & 5.50 & 6.00 & 5.50 & 8.00 \\
\hline & Total & 2.68 & 3.16 & 5.16 & 5.89 & 5.84 & 7.29 \\
\hline
\end{tabular}

Fuente: Elaboración propia con datos de la encuesta nacional ICSO-UDP 2011 y de la encuesta a congresistas ICSO-UDP 2011-2012. La pregunta que se formula tanto para la ciudadanía como para los congresistas es la siguiente: "De acuerdo a lo que ha visto y en una escala de 1 a 10, la sociedad chilena es...Democrática/Autoritaria, Pacífica/Violenta, Justa/Injusta, Tolerante/Discriminadora, No racista/Racista, No clasista/Clasista.

Gráfica 10. Diferencias promedio entre las percepciones de los congresistas y la ciudadanía sobre la sociedad chilena

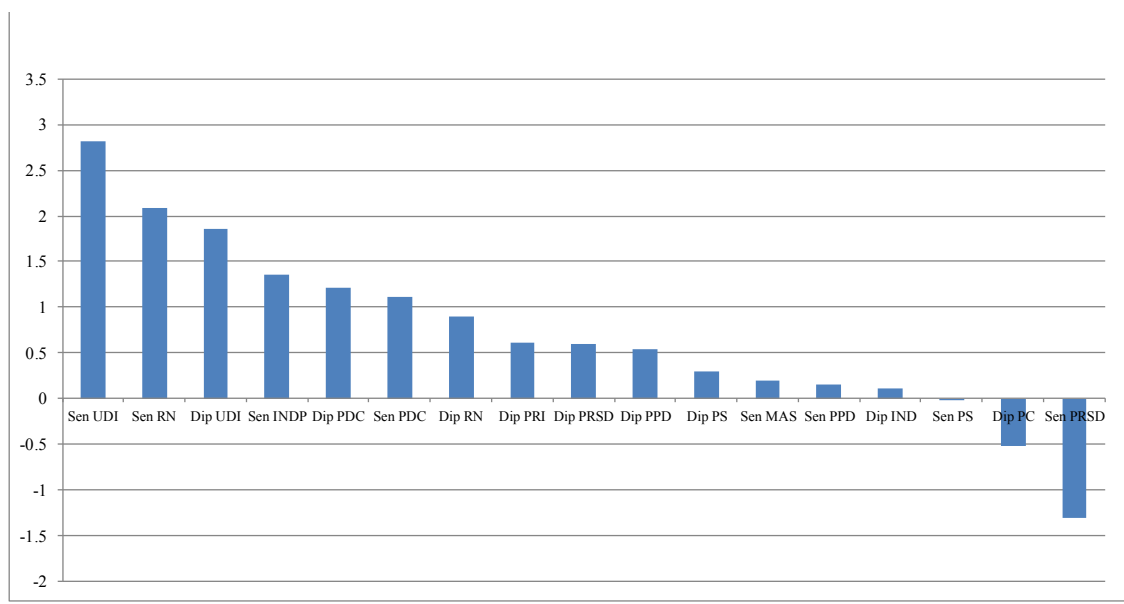

Fuente: Elaboración propia con datos de la encuesta nacional ICSO-UDP 2011 y de la encuesta a congresistas ICSO-UDP 2011-2012.

Los resultados indican que las bancadas más lejanas de la media nacional son las de diputados y senadores de la UDI y los senadores de RN. Es importante subrayar que mientras en el resto de los partidos las bancadas de senadores y diputados son relativamente cercanas entre sí, en el caso de RN hay una distancia más o menos significativa entre ellas. Por ejemplo, 
mientras los senadores de RN están distanciados de la media nacional en más de dos puntos, los diputados están distanciados en sólo 0.89 puntos. Algo similar ocurre con el PRSD, aunque en éste los casos son reducidos y se contabiliza un solo senador.

\section{Conclusiones}

En este artículo se discuten algunos supuestos generalizados sobre el caso de Chile. Por un lado, se le destaca como un ejemplo de institucionalización de su sistema de partidos. Por otro, se clasifica como uno de los países con mayor estructuración programática de las preferencias. De acuerdo a la evidencia, ambos supuestos son, al menos, discutibles. Si bien Chile posee niveles de volatilidad bajos en el contexto latinoamericano, los niveles de identificación con partidos han decrecido de manera más acelerada que en el resto de la región. Al mismo tiempo, es poco convincente el argumento de que Chile es un país con altos niveles de congruencia programática. Como se constató en el análisis de datos, esto es plausible al observar las medidas agregadas; es decir, comparando el total de legisladores con el de los ciudadanos. La interpretación cambia de manera sustantiva cuando la comparación se hace por coaliciones y partidos.

Lo anterior conduce a repensar el sistema de partidos chileno. Poco a poco se ha transitado desde un sistema institucionalizado a otro de carácter hidropónico, o sea, estable en términos de los patrones de votación por las coaliciones, pero con bajos niveles de identificación con partidos. A esto se suma el hecho de que el partido más congruente con los ciudadanos es el que más ha bajado su votación, mientras que el partido más incongruente la ha aumentado de manera sustantiva. Bajo estas circunstancias es posible avanzar en nuevas interpretaciones sobre el caso de Chile. La particularidad del caso radica en que la proximidad programática no sea sinónimo de apoyo electoral o que, incluso, produzca el efecto contrario. Esto se explica porque en un escenario de polarización ideológica, la proximidad programática es condición necesaria (y a veces suficiente) para generar adhesión electoral. En cambio, en escenarios de baja polarización, la proximidad programática no es condición necesaria ni suficiente. Cuando se debilitan los clivajes que ordenan las preferencias políticas de los ciudadanos, la intensidad de los partidos emerge con mayor fuerza y se refleja en el número de liderazgos que son valorados por la ciudadanía y en la capacidad de esos líderes para sintonizar con las demandas ciudadanas más inmediatas. En consecuencia, lo que se requiere en este tipo de contextos, más que 
proximidad ideológica o programática con los electores, es intensidad en el planteamiento de las agendas. En otras palabras, lo que se necesita es una proximidad pragmática hacia los electores y no necesariamente una proximidad ideológica.

La proximidad pragmática no sólo tiene que ver con la capacidad de los líderes del partido para reflejar de manera genuina las demandas más inmediatas de la ciudadanía, también con la capacidad del partido para distribuir recursos. En el caso de Chile, la UDI tiene un fuerte arraigo en el mundo empresarial, lo que le facilita la obtención de recursos para gastar en campañas. Como se mostró anteriormente, la UDI es el partido que más gasta en campaña, lo que le permite competir en los segmentos populares, antiguos reductos de los partidos de izquierda.

El estudio de Chile, en consecuencia, es útil para analizar con más precisión algunos supuestos de los enfoques de la institucionalización partidaria y de la vinculación entre partidos y electores. La supuesta relación lineal entre vinculación, institucionalización y calidad de la democracia es perfectamente cuestionable. Al mismo tiempo, y dentro del índice de institucionalización, es plausible encontrar casos que combinen, por ejemplo, alta estabilidad en las tendencias electorales de los partidos (baja volatilidad) y bajo arraigo social de los partidos (baja identificación).

\section{Bibliografía}

Abente, Diego, 2009, "Paraguay: The unraveling of One-Party Rule", Journal of Democracy, vol. 20, núm. 1, pp. 143-156.

Adams, James, 2001, Party Competition and Responsible Party Government, Michigan, University of Michigan Press.

Alcántara Sáez, Manuel, 2006, Políticos y política en América Latina, Madrid, Siglo XXI.

Artiga, Álvaro, 2000, La política y los sistemas de partidos en Centroamérica, San Salvador, Fundación Dr. Guillermo Manuel Ungo.

Ashworth, Scott y Ethan Bueno de Mesquita, 2007, "Valence Competition and Platform Divergence", University of Chicago, Harris School of Public Policy, Manuscrito.

Belchior, Ana Maria, 2010, “Ideological Congruence among European Political Parties", The Journal of Legislative Studies, vol. 16, núm. 1, pp. 121-142. 
Budge, Ian y Michael D. McDonald, 2007, “Election and Party System Effects on Policy Representation: Bringing Time into Comparative Perspective", Electoral Studies, vol. 26, núm. 1, pp. 168-179.

Converse, Phillip E. y Roy Pierce, 1986, Political representation in France, Cambridge, Berlknam Press of Harvard University Press.

Coppedge, Michael, 2001, "Party Systems, Governability, and the Quality of Democracy in Latin America", Trabajo presentado en la conferencia Representation and Democratic Politics in Latin America, Universidad de San Andrés y University of Pittsburgh, Buenos Aires, Argentina, Junio 7-8.

Dalton, Russell, 1985, "Political Parties and Political Representation. Party Supporters and Party Elites in Nine Nations", Comparative Political Studies, vol. 18, núm. 3, pp. 267-299.

Golder, Matt y Jacek Stramski, 2010, “Ideological Congruence and Electoral Institutions", American Journal of Political Science, vol. 54, núm. 1, pp. 90-106.

Hagopian, Frances, 1998, “Democracy and Political Representation in Latin America in the 1990s: Pause, Reorganization, or Decline?", en Felipe Agüero y Jeffrey Stark (eds.), Fault Lines of Democracy in Post-Transitional Latin America, Boulder, North-South Center Press, pp. 99-143.

Hallerberg, Mark y Patrik Marier, 2004, “Executive Authority, the Personal Vote, and Budget Discipline in Latin American and Caribbean Countries", American Journal of Political Science, vol. 48, núm. 3, pp. 571-587.

Huneeus, Carlos, 2003, Chile. Un país dividido. Santiago, Catalonia.

Iversen, Torben. 1994, "Political Leadership and Representation in European Democracies: A Test of Three Models of Voting", American Journal of Political Science, vol. 38, núm. 1, pp. 45-74.

Jacobs, Lawrence R. y Robert Y. Shapiro, 2002, "Politics and Policymaking in the Real World: Crafted Talk and the Loss of Democratic Responsiveness", en J. Manza, F. Lomas Cook y B.I. Page (eds.), Navigating Public Opinion: Polls, Policy, and the Future of American Democracy, Nueva York, Oxford University Press.

Kitschelt, Herbert, Kirk Hawkins, Juan Pablo Luna, Guillermo Rosas y Elizabeth Zechmeister, 2010, Latin American Party Systems, Nueva York, Cambridge University Press. 
Kitschelt, Herbert, Zdenka Mansfeldová, Radoslaw Markowski y Gábor Tóka, 1999, Post-Communist Party Systems: Competition, Representation, and Inter-Party Cooperation, New York, Cambridge University Press.

Levine, Daniel y José Molina, 2007, “La Calidad de la Democracia en América Latina: Una Visión Comparada", América Latina Hoy, vol. 45, abril, pp. 17-46.

Luna, Juan Pablo, 2010, “Segmented Party Voter Linkages in Latin America: The Case of the UDI", Journal of Latin American Studies, vol. 42, pp. 325-356.

Luna, Juan Pablo, 2008, "Partidos políticos y sociedad en Chile. Trayectoria histórica y mutaciones recientes", en Reforma de los partidos políticos en Chile. Santiago, PNUD, CEP, Proyectamérica, Instituto Libertad y Desarrollo y CIEPLAN.

Luna, Juan Pablo, 2007, “Representación política en América Latina: el estado de la cuestión y una propuesta de agenda", Política y gobierno, vol. 14, núm 2, pp. 391-435.

Luna, Juan Pablo y David Altman, 2011, “Uprooted but Stable: Chilean Parties and the Concept of Party System Institutionalization", Latin American Politics and Society, vol. 53, núm. 2, pp. 1-28.

Luna, Juan Pablo y Elizabeth J. Zechmeister, 2010, “Political Representation in Latin America", en H. Kitschelt, K. Hawkins, J. Luna, G. Rosas y E. Zechmeister (eds.), Latin American Party Systems, Cambridge, Cambridge University Press, pp. 119-168.

Luna, Juan Pablo y Elizabeth J. Zechmeister, 2005, “The Quality of Representation in Latin America: A Study of Elite-Mass Congruence in Nine Countries", Comparative Political Studies, vol. 38, núm 4, pp. 388-416.

Magar, Iván, Marc R. Rosenblum y David Samuels, 1998, “On the Absence of Centripetal Incentives in Double-Member Districts: The Case of Chile", Comparative Political Studies, vol. 31, núm. 6, pp. 714-739.

Mainwaring, Scott, 1999, Rethinking Party Systems in the Third Wave of Democratization: The Case of Brazil, Stanford, Stanford University Press.

Mainwaring, Scott y Timothy R. Scully, 1995, “La institucionalización de los Sistemas de Partidos en América Latina”, Revista de Ciencia Política vol. 17, núm 1-2, pp. 63-102. 
Mainwaring, Scott y Mariano Torcal, 2005, “La institucionalización de los sistemas de partidos y la teoría del sistema partidista después de la tercera ola democratizadora", América Latina Hoy, vol. 41, diciembre, pp. 141-173.

Mainwaring, Scott, Ana María Bejarano y Eduardo Pizarro Leongómez (eds.), 2006, The Crisis of Democratic Representation in the Andes, Stanford, Stanford University Press.

Meirowitz, Adam, 2008, "Electoral Contests, Incumbency Advantages and Campaign Finance", Journal of Politics, vol. 80, núm. 3, pp.681-99.

Miller, Warren E. y Donald E. Stokes, 1963, “Constituency Influence In Congress”, American Political Science Review, vol. 57, núm. 1, pp. 45-56.

Morales, Mauricio, 2014, Identificación partidaria en América Latina. Instituciones, historia y votantes. Tesis para la obtención del grado de Doctor en Ciencia Política, Santiago, Pontificia Universidad Católica de Chile.

Morales, Mauricio, 2012, "Identificación partidaria en América Latina", Revista de Estudios Sociales, vol. 17, núm. 4, pp. 583-597.

Morales, Mauricio, 2012a, “The Concertación's Defeat in the 2009/2010 Presidential Elections in Chile", Latin American Politics and Society, vol. 54, núm. 2, pp. 79-107.

Morales, Mauricio, 2011, "Precauciones frente al voto voluntario", en Chile 2010, Sexta Encuesta Nacional UDP. Percepciones y actitudes sociales, pp. 59-72.

Morales, Mauricio. 2010, “¿Quiénes son, dónde están, qué quieren?: las bases electorales de los candidatos presidenciales 2009", en Chile 2009: actitudes y percepciones sociales, Reporte de Encuesta Nacional UDP 2009, pp. 27-38.

Morales, Mauricio y Rafael Piñeiro, 2010, “Gasto en campaña y éxito electoral de los candidatos a diputados en Chile 2005", Revista de Ciencia Política, vol. 30, núm. 3, pp. 645-667.

Morales, Mauricio y Patricio Navia, 2010, El sismo electoral de 2009. Cambio y continuidad en las preferencias políticas de los chilenos, Santiago, Ediciones UDP.

Morgan, Jana, 2007, “Partisanship During the Collapse of Venezuela's Party System”, Latin American Research Review, vol. 42, núm. 1, pp. 78-98. 
Morgan, Jana, 2003, "Counting on the Past or Investing in the Future? Economic and Political Accountability in Fujimori's Peru", Journal of Politics, vol. 65, núm. 3, pp. 864-880.

Navia, Patricio, 2005, La transformación de votos en escaños: leyes electorales en Chile, 1833-2004", Política y Gobierno, vol. 12, núm. 2, pp. 233-276.

O'Donnell, Guillermo, 1997, Contrapuntos. Ensayos escogidos sobre autoritarismo y democratización, Buenos Aires, Paidós.

Payne, Mark, Daniel Zovatto, Fernando Carrillo y Andrés Allamand, 2003, La politica importa. Democracia y desarrollo en América Latina, Washington, D.C., BID e Instituto Internacional para la Democracia y la Asistencia Electoral.

Powell, G. Bingham, 2009, “The Ideological Congruence Controversy: The Impact of Alternative Conceptualizations and Data on the Effects of Election Rules", Comparative Political Studies, vol. 42, núm. 12, pp. 1475-1497.

Przeworski, Adam, 1997, “Democracy and Representation”, Trabajo presentado en el II Congreso Internacional del CLAD sobre la Reforma del Estado y de la Administración Pública, Isla Margarita, Venezuela, 14 -18 de octubre.

Rabinowitz, George y Stuart Macdonald, 1989, “A Directional Theory of Issue Voting", American Political Science Review, vol. 83, núm. 1, pp. 93-121.

Roberts, Kenneth, 2002, "Party-society linkages and democratic representation in Latin America", Canadian Journal of Latin American and Caribbean Studies, vol. 27, núm. 53, pp. 9-34.

Samuels, David J. y Matthew Shugart, 2003, "Presidentialism, Elections and Representation”, Journal of Theoretical Politics, vol. 15, núm. 1, pp. 33-60.

Serra, Gilles, 2010, "Polarization of What? A Model of Elections with Endogenous Valence", The Journal of Politics, vol. 72, núm. 2, pp. 426-437.

Siavelis, Peter M., 2009, "Elite-Mass Congruence, Partidocracia and the Quality of Chilean Democracy", Journal of Politics in Latin America, vol. 1, núm. 3, pp. 3-31.

Stokes, Susan C., 2001, Mandates and Democracy: Neoliberalism by Surprise in Latin America, Cambridge, Cambridge University Press.

Torcal, Mariano, 2001, “La Desafección en las Nuevas Democracias del Sur de Europa y Latinoamérica”, Instituciones y Desarrollo, vol. 8/9, mayo, pp. 229-280. 
Torres-Rivas, Edelberto, 2007, La piel de Centroamérica. Una mirada epidérmica de setenta y cinco años de su historia, FLACSO, Costa Rica.

Weyland, Kurt, 2004, "Neoliberalism and Democracy in Latin America: A Mixed Record", Latin American Politics and Society, vol. 46, núm. 1, pp. 135-157.

Zucco, Cesar, 2009, "Stability Without Roots: Party System Institutionalization in Brazil", Working paper, Rio de Janeiro, Instituto Universitário de Pesquisas do Rio de Janeiro.

Recibido el 21 de junio de 2012 Aceptado el 24 de septiembre de 2013 